\title{
PENERAPAN MANAJEMEN PROYEK DENGAN METODE CPM (Critical Path Method) PADA PROYEK PEMBANGUNAN SPBE
}

\author{
Surya Perdana ${ }^{1}$, Arif Rahman ${ }^{2}$ \\ Program Studi Teknik Industri Universitas Indraprasta PGRI, Jakarta \\ suryaperdana.st.mm@gmail.com
}

\begin{abstract}
ABSTRAK
Sebuah perusahaan konstruksi yang bergerak dibidang pembangunan infrastruktur Stasiun Pengisian Bahan Bakar Elpiji (SPBE) sedang menjalankan banyak proyek pada beberapa wilayah di Indonesia. Dengan jadwal proyek yang begitu padat, maka perlu adanya manajemen proyek yang baik dalam menjalankannya. Kegiatan ini bertujuan untuk memberikan pemahaman kepada para karyawan perusahaan mengenai manajemen proyek dengan metode Critical Path Method (CPM) agar karyawan dapat menyelesaikan seluruh proyek yang sedang berjalan. Metode yang digunakan dalam pelaksaan pengabdian kepada masyarakat ini dibagi menjadi dua tahap, pada tahap pertama dilakukan observasi langsung, yaitu: tim abdimas datang ke lokasi dalam rangka memperoleh data. Hal ini dilakukan pada saat menjelang maupun pada saat kegiatan berlangsung. Tahap kedua adalah pelatihan, yaitu: tim memberikan materi tentang manajemen proyek dengan metode Critical Path Method (CPM) sekaligus memecahkan permasalahan yang dihadapi oleh perusahaan. Hasil dari pengabdian kepada masyarakat ini adalah para karyawan dapat merencanakan dan menjalankan proyek sesuai target dengan metode Critical Path Method (CPM).
\end{abstract}

Kata kunci: Critical Path Method (CPM), Manajemen Proyek, SPBE

\begin{abstract}
A construction company engaged in infrastructure development of the LPG Fuel Filling Station (SPBE) is carrying out many projects in several regions in Indonesia. With a very tight project schedule, it is necessary to have good project management in running it. This activity aims to provide understanding to company employees regarding project management with the Critical Path Method (CPM) method so that employees can complete all ongoing projects. The method used in the implementation of community service is divided into two stages, in the first stage direct observation is carried out, namely: the abdimas team comes to the location in order to obtain data. This is done both before and during the activity. The second stage is training, namely: the team provides material about project management with the Critical Path Method (CPM) method while solving the problems faced by the company. The result of this community service is that employees can plan and run projects according to target with the Critical Path Method (CPM) method.
\end{abstract}

Keyword: Critical Path Method (CPM), Project Management, SPBE

\section{PENDAHULUAN}

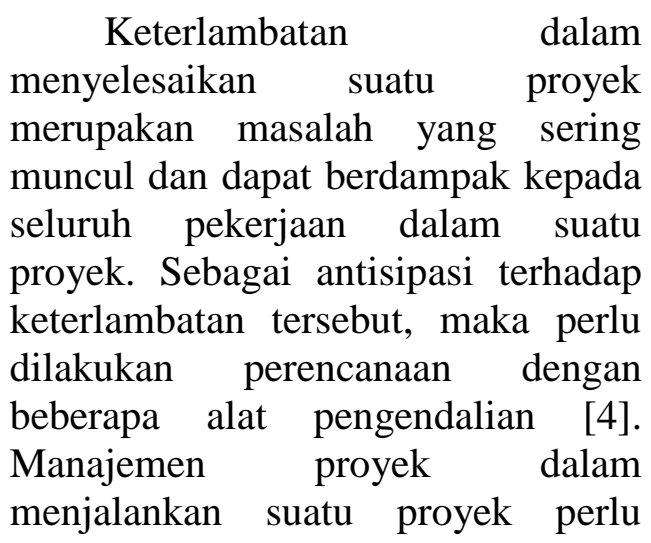

dibuat agar terhindar dari kegagalan dan resiko proyek. Manajemen yang baik harus dapat mengelola menejemen aktivitas seperti penjadwalan proyek, pengelolaan human resource yang terlibat langsung dalam suatu proyek sehingga akan berujung pada estimasi biaya proyek yang perlu dianggarkan oleh suatu perusahaan [1].

Dengan melakukan penjadwalan pada suatu proyek, 
maka akan membantu perusahaan untuk mengetahui hubungan antara aktivitas dalam proyek dan hubungan aktivitas terhadap keseluruhan proyek. Perusahaan juga dapat mengidentifikasi setiap hubungan aktivitas dalam suatu proyek yang harus didahulukan, serta perusahaan dapat mengetahui perkiraan waktu yang realistis dalam menjalankan setiap aktivitas yang ada dalam suatu proyek [5].

Sebuah perusahaan konstruksi yang bergerak dibidang pembangunan infrastruktur Stasiun Pengisian Bahan Bakar Elpiji (SPBE) sedang menjalankan banyak proyek pada beberapa wilayah di indonesia. dengan jadwal proyek yang begitu padat, maka perlu adanya manajemen proyek yang baik dalam menjalankannya. kegiatan pengabdian kepada masyarakat ini bertujuan untuk memberikan pemahaman kepada para karyawan perusahaan mengenai manajemen proyek dengan metode Critical Path Method (CPM) agar karyawan dapat menyelesaikan seluruh proyek yang sedang berjalan dengan tepat waktu. CPM merupakan analisa jaringan kerja yang berusaha mengoptimalkan biaya total proyek melalui pengurangan atau percepatan waktu penyelesaian total proyek yang bersangkutan [3].

Fungsi dari manajemen proyek adalah [1]:

\section{Fungsi perencanaan (Planning)}

Bertujuan dalam pengambilan keputusan yang mengelola data dan informasi yang dipilih untuk dilakukan di masa mendatang, seperti menyusun rencana jangka panjang dan jangka pendek, dan lain-lain.
2. Fungsi Organisasi (Organizing)

Bertujuan untuk mempersatukan kumpulan kegiatan manusia, yang memiliki aktivitas masingmasing dan saling berhubungan, dan berinteraksi dengan lingkungannya dalam rangka mencapai tujuan organisasi, seperti menyusun lingkup aktivitas.

3. Fungsi Pelaksanaan (Actuating)

Bertujuan untuk menyelaraskan seluruh pelaku organisasi terkait dalam melaksanakan kegiatan/ proyek, seperti pengarahan tugas serta motivasi.

4. Fungsi Pengendalian (Controlling)

Bertujuan untuk mengukur kualitas penampilan dan penganalisisan serta pengevaluasian kegiatan, seperti memberikan saran-saran perbaikan.

Keterlambatan jadwal dari rencana yang telah disusun pada proyek konstruksi merupakan salah satu masalah yang dapat memberikan kerugian untuk berbagai pihak pada proyek. Penjadwalan proyek merupakan salah satu elemen penting, karena penjadwalan memberikan informasi tentang kemajuan proyek dalam hal kinerja sumber daya, biaya, tenaga kerja, peralatan, material serta rencana durasi proyek dan progres waktu untuk penyelesaian proyek. Progres waktu yang ditampilkan dalam jadwal proyek menjadi salah satu elemen penting dalam pengendalian waktu proyek. Karena dengan mengetahui progres rencana dana aktual satu proyek, maka kita 
dapat mengetahui seberapa jauh proyek tersebut terlambat atau lebih cepat [2].

CPM pada dasarnya adalah merupakan metode yang berorientasi pada waktu, dalam arti bahwa CPM akan berakhir pada penentuan waktu. Metode ini mengidentifikasi jalur kritis pada aktifitas yang ditentukan ketergantungan antar aktifitasnya. Aktifitas merupakan tugas spesifik yang mempunyai hasil yang dapat diukur dari durasi pengerjaannya Jalur kritis adalah suatu deretan kegiatan kritis yang menentukan jangka waktu penyelesaian bagi keseluruhan proyek [6]. Penggambaran Critical Path Method menggunakan simbol yang dapat berbentuk segi empat atau lingkaran. Di bawah ini adalah gambar contoh penggambaran CPM untuk satu item pekerjaan [6].

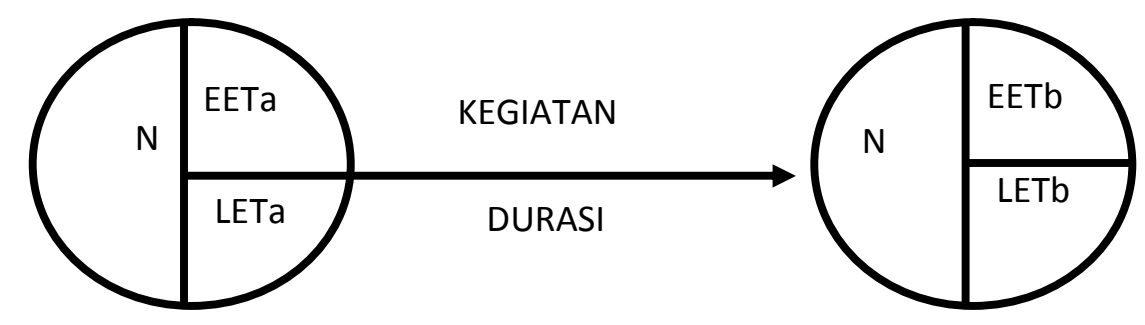

Gambar 1. Diagram CMP untuk satu item pekerjaan

Keterangan :

a. Lingkaran disebut juga node menunjukkan berawalnya suatu pekerjaan ataupun berakhirnya suatu pekerjaan

b. Garis panah (arrow) menunjukkan pekerjaan, arah panah ke suatu node menunjukkan urutan antar pekerjaan.

c. EETa : Saat paling awal pekerjaan dimulai

d. EETb : Saat paling dini pekerjaan berakhir

e. LETa : Saat paling lambat pekerjaan dimulai

f. LETb : Saat paling lambat pekerjaan berakhir

g. Durasi : Lama pekerjaan berlangsung

h. $\mathrm{N}$ pengidentifikasian node
Faktor-faktor yang harus dipertimbangkan dalam membuat jadwal pelaksanaan proyek [8]:

1. Kebutuhan dan fungsi proyek tersebut. Dengan selesainya proyek itu diharapkan dapat dimanfaatkan sesuai dengan waktu yang sudah ditentukan

2. Alasan sosial politis lainnya, apabila proyek tersebut milik pemerintah.

3. kondisi alam dan lokasi proyek.

4. keterjangkauan lokasi proyek ditinjau dari fasilitas perhubungannya.

5. Sumber daya material, peralatan, dan material pelengkap lainnya yang menunjang terwujudnya proyek tersebut.

6. Kapasitas area kerja proyek terhadap sumber daya yang 
dipergunakan selama operasional pelaksanaan berlangsung.

7. Sumber daya, peralatan proyek dan tenaga kerja proyek, selama operasional berlangsung dengan referensi dan perhitungan yang memenuhi aturan teknis.

Beberapa hal yang digunakan sebagai pedoman dalam pembuatan network diagram adalah sebagai berikut [7]:
1. Dalam penggambaran, network diagram harus jelas dan mudah untuk dibaca.

2. Dimulai dari event/kejadian dan diakhiri pada event/kejadian.

3. Kegiatan disimbolkan dengan anak panah yang digambar garis lurus dan boleh patah.

4. Dihindari terjadinya perpotongan antara anak panah.

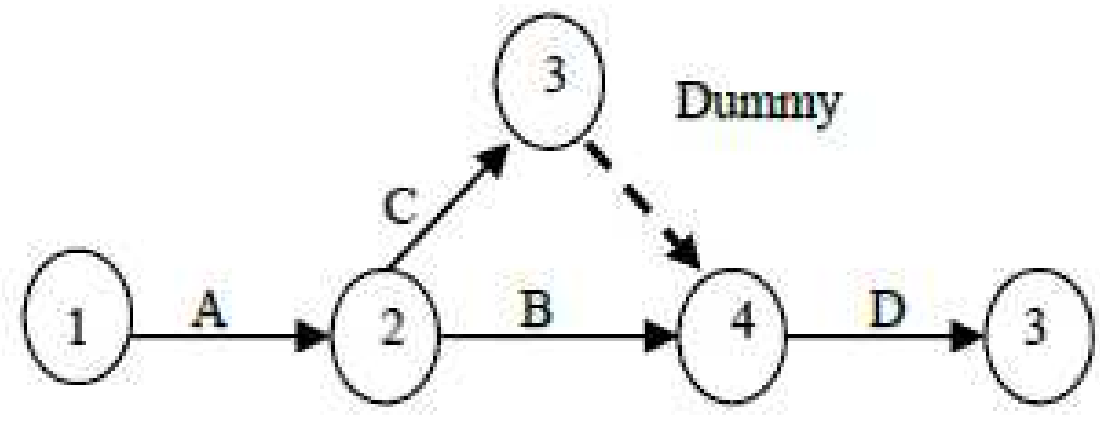

Gambar 2. Network diagram AOA

Untuk membentuk visualisasi dari network planning, perlu digunakan simbol-simbol yaitu [7]:

1. $\rightarrow$ Arrow, (anak panah), menyatakan sebuah kegiatan/aktivitas yang memerlukan durasi (jangka waktu tertentu).

2. $\bigcirc$ Node, merupakan lingkaran yang menyatakan sebuah kegiatan atau peristiwa (event) sebagai awal atau akhir atau pertemuan dari satu atau beberapa kegiatan.

3. $\rightarrow$ Double

Arrow, bentuknya merupakan arah panah sejajar, yang menunjukkan kegiatan lintasan kritis (critical path).
4. ... Dummy, bentuknya merupakan arah panah terputusputus yang menyatakan kegiatan semu untuk membatasi mulainya kegiatan.

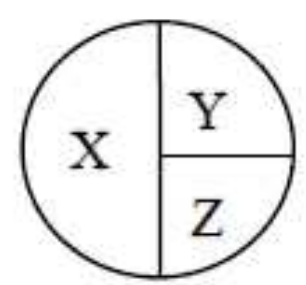

Gambar 3. Event (Lingkaran kejadian)

Bila suatu lingkaran kejadian dibagi menjadi 3 ruang yang mempunyai arti sebagai berikut [7]:

Ruang X, Yang terletak disebelah kiri disediakan untuk nomor 
lingkaran kejadian (Number of event).

Ruang Y, Yang terletak di sebelah kiri disediakan untuk menunjukkan "waktu" paling awal peristiwa itu dapat dikerjakan (EET = Earliest Event Time)

Ruang Z, Yang terletak pada bagian kanan bawah disediakan untuk menunjukkan "waktu paling akhir peristiwa itu dapat dikerjakan" (LET = Latest Event Time).

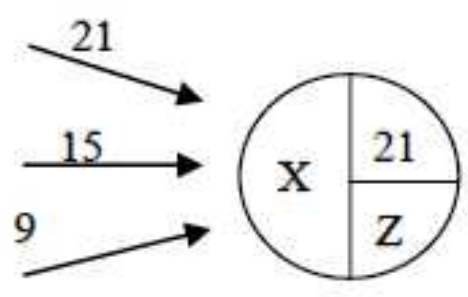

Gambar 4. Contoh event dengan perhitungan EET

Untuk mempermudah Network Planning di dalam mencari jalur kritis. Perhitungan EET dilakukan melalui event awal bergerak ke event akhir dengan cara menjumlahkan, yaitu antara EET ditambah durasi. Dan bila pada suatu event bertemu dua atau lebih kegiatan, EET yang dipakai adalah waktu yang terbesar.

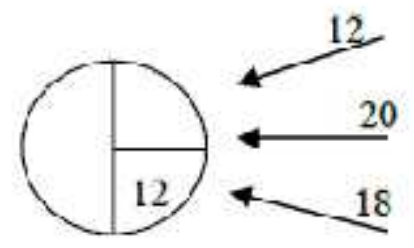

Gambar 5. Contoh event dengan perhitungan LET

Menghitung LET dilakukan mulai dari event akhir bergerak mundur dengan jalan mengurangi, yaitu antara LET dikurangi durasi. Dan apabila pada suatu event

Lintasan kritis merupakan jumlah waktu pelaksanaan di dalam suatu event yang tidak boleh dilampaui dalam melaksanakan suatu rangkaian kegiatan. Lintasan kritis terjadi pada suatu event yang mempunyai: EET = LET [7].

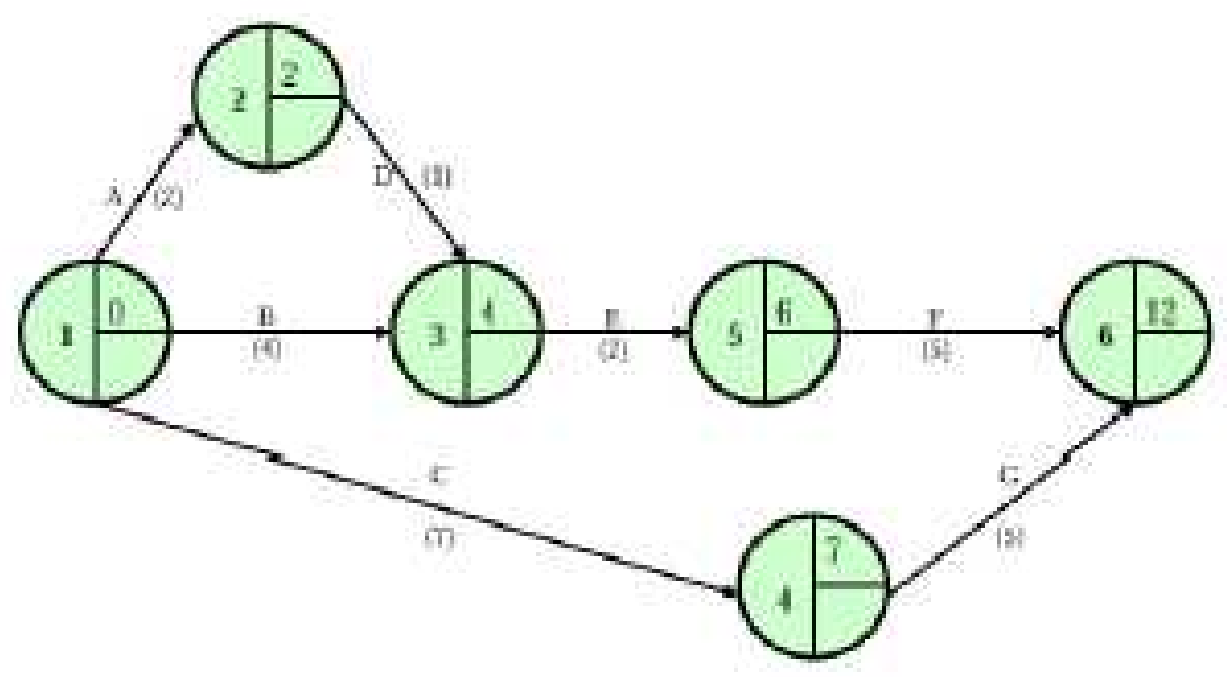

Gambar 6. Network Diagram EET (Saat paling cepat terjadi) 
1. Mulai dari event yang pertama kearah kanan menuju event yang terakhir. kegiatan maka yang menentukan adalah hasil penjumlahan yang terbesar.

2. Dengan cara penjumlahan.

3. Apabila EET dari satu event tergantung oleh lebih dari satu

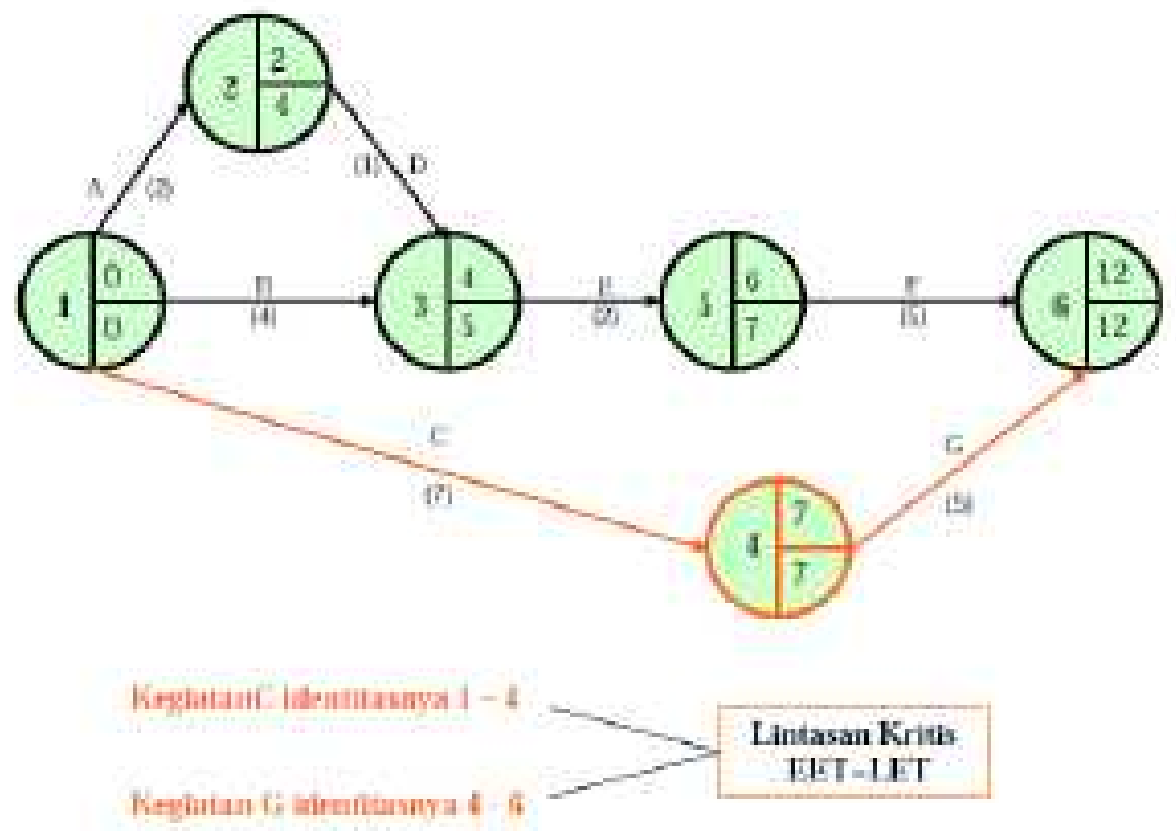

Gambar 7. Network Diagram LET (Saat paling lambat terjadi)

1. Mulai dari event yang terakhir kearah kiri menuju event yang pertama dengan cara pengurangan.

2. Apabila LET dari suatu event tergantung pada lebih dari satu kegiatan, maka yang menentukan adalah hasil pengurangan yang terkecil.

\section{METODE PELAKSANAAN}

Kegiatan pelatihan Manajemen Proyek dengan Metode Critical Path Method (CPM) ini dilaksanakan di kantor PT. RJM Kota Tangerang. Kegiatan abdimas ini dilakukan dengan metode penyuluhan, diskusi, dan juga tanya jawab oleh para karyawan.

Kegiatan

pengabdian masyarakat ini dimulai dari bulan Januari 2017 sampai dengan Maret 2017, dengan tahapan sebagai berikut:

a. Melakukan survey ke PT. RJM dan diskusi dengan Direktur PT. RJM mengenai materi yang sesuai untuk karyawan mengenai manajemen proyek.

b. Proses persiapan sosialisasi Manajemen Proyek dengan Metode Critical Path Method 
(CPM) kepada karyawan PT. RJM.

c. Melakukan penyuluhan kepada karyawan dengan metode diskusi dan tanya jawab

Kegiatan abdimas ini dilakukan atas dasar izin dari pihak perusahaan, yaitu PT. RJM. Kegiatan abdimas ini diawali dengan observasi lapangan untuk mengetahui target kegiatan, kondisi karyawan yang akan diberikan pelatihan dan menyusun rancangan kegiatan yang akan dilakukan.

Kegiatan berikutnya adalah melakukan penyuluhan sosialisasi mengenai Manajemen Proyek dengan Metode Critical Path Method (CPM) kepada karyawan PT. RJM di dalam ruangan sehingga para karyawan dapat melihat, dan bisa memahami pelatihan yang disampaikan. Kegiatan dilaksanakan di dalam salah satu ruangan di PT. RJM. Dengan materi yang disampaikan diharapkan karyawan dapat membuat penjadwalan proyek dengan baik sehingga pengerjaan proyek dapat tepat waktu. Setelah diberikan pelatihan selanjutnya karyawan akan masuk dalam sesi diskusi dan tanya jawab antara karyawan dengan tim abdimas.

\section{HASIL PEMBAHASAN}

Kegiatan pelatihan Manajemen Proyek dengan Metode Critical Path Method (CPM) untuk menambah wawasan memahami konsep CPM dengan baik dan mengaplikasikannya dalam menjalankan suatu proyek kepada para karyawan PT. RJM Kota Tangerang, yang dilakukan oleh tim abdimas dari Universitas Indraprasta PGRI Jakarta yang beranggotakan 3 (tiga) orang Dosen. Kegiatan dilaksanakan terhadap para karyawan di ruang kantor. Kegiatan ini diawali dengan observasi kepada mitra tersebuat pada bulan Januari 2017 untuk mengumpulkan informasi, mengenai materi yang sesuai untuk karyawan mengenai manajemen proyek.

Di bulan Maret minggu pertama, tim abdimas melakukan pembuatan materi untuk memudahkan penyuluhan pembelajaran. Pada bulan Maret minggu ketiga melaksanakan kegiatan pelatihan. Berdasarkan sosialisasi kegiatan pelatihan ini, diperoleh hasil sebagai berikut: a. Para karyawan sangat antusias dengan materi yang disampaikan oleh tim abdimas; b. Para Karyawan mendapatkan wawasan mengenai bagaimana membuat penjadwalan proyek dengan baik sehingga pengerjaan proyek dapat tepat waktu, juga memahami konsep CPM dengan baik dan mengaplikasikannya dalam menjalankan suatu proyek.

Kegiatan pelatihan Manajemen Proyek dengan Metode Critical Path Method (CPM) yang dilakukan bermanfaat sekali bagi karyawan PT. RJM. Dukungan dari direktur PT. RJM yang telah menginstruksikan para karyawan agar serius dan fokus dalam mengikuti kegiatan ini patut diapresiasi, mulai dari perkenalan, penyampaian materi sampai akhir pelatihan. 

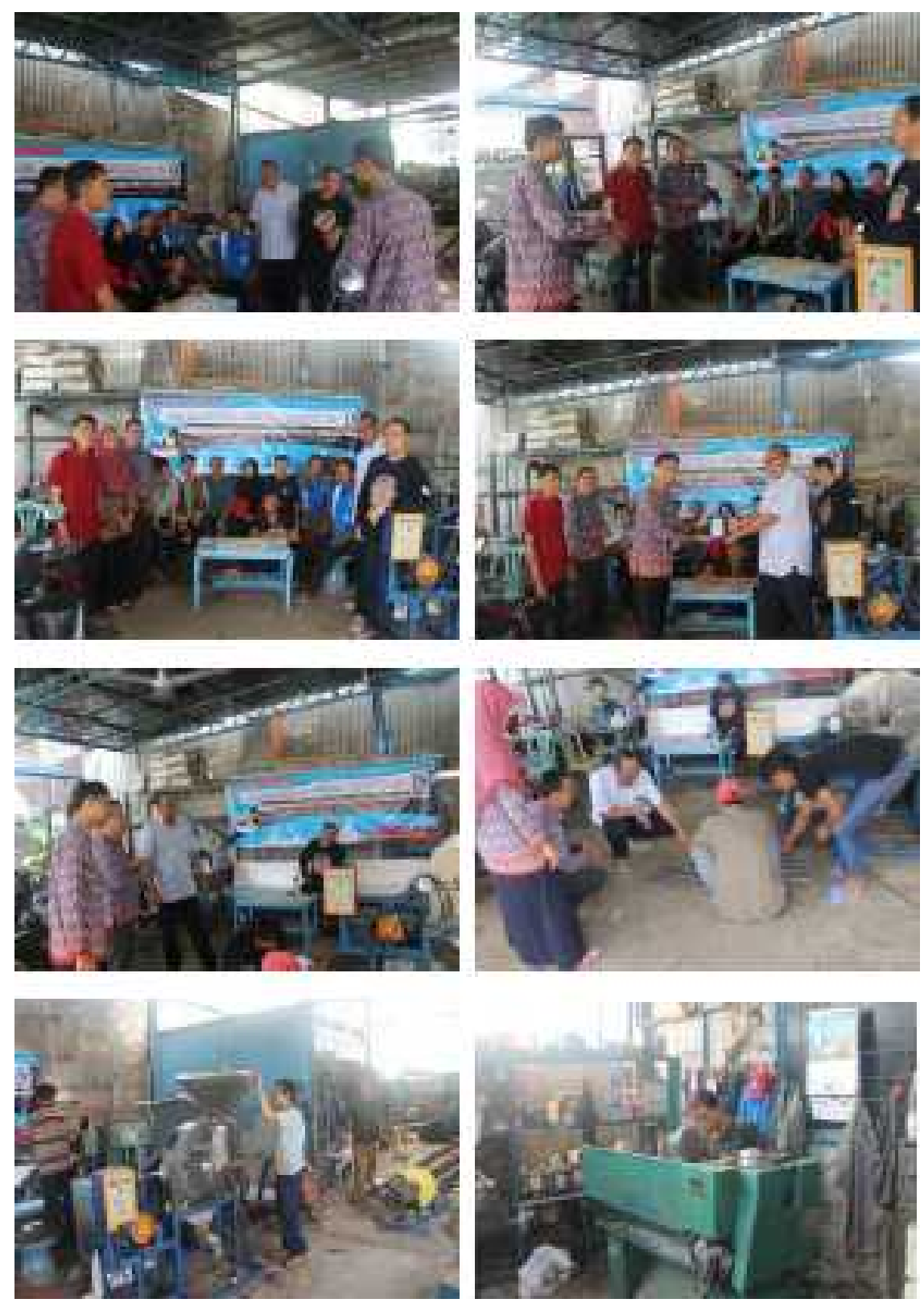

Gambar 8. Dokumentasi kegiatan Abdimas di PT. RJM

Dengan

wawasan/pengetahuan
Manajemen Proyek dengan metode CPM, sehingga secara keseluruhan proses kegiatan abdimas dapat terlaksana dengan baik. Dapat disimpulkan bahwa kegiatan ini dapat meningkatkan kemampuan, pengetahuan, wawasan dan motivasi para karyawan PT. RJM dalam melaksanakan pekerjaannya.

\section{KESIMPULAN}

Pelaksanaan pengabdian pada masyarakat yang telah dilaksanakan di PT. RJM Kota Tangerang berjalan dengan baik. Hasil dari pengabdian ini karyawan PT. RJM mendapatkan wawasan mengenai bagaimana membuat penjadwalan proyek dengan baik sehingga pengerjaan proyek dapat tepat waktu dan mendapat pemahaman 
tentang konsep CPM dengan baik, serta dapat mengaplikasikannya dalam menjalankan suatu proyek.

Kegiatan abdimas ini tidak akan berjalan dengan baik tanpa dukungan semua pihak, khususnya dari mitra yaitu Direkur PT. RJM beserta karyawannya, dan juga dari tim abdimas Universitas Indraprasta PGRI sehingga pelaksanaan abdimas berjalan dngan baik.

\section{REFERENSI}

Arianie, G. P. \& Puspitasari, N. B. (2017). Perencanaan Manajemen Proyek Dalam Meningkatkan Efisiensi dan Efektifitas Sumber Daya Perusahaan (Studi Kasus : Qiscus Pte Ltd). J@ti Undip: Jurnal Teknik Industri, Vol. 12, No. 3, September 2017.

Aulady, M., \& Orleans, C. (2016). Perbandingan Durasi Waktu Proyek Konstruksi Antara Metode Critical Path Method (CPM) dengan Metode Critical Chain Project Management (Studi Kasus: Proyek Pembangunan Apartamen Menara Rungkut). Jurnal IPTEK Vol.20 No.1, Mei 2016.

Banjarnahor, W. W. D., \& Pristiwanto. (2018). Analisis Pelaksanaan Proyek Perumahan Dengan Metode CPM (Critical Path Method) dan PERT (Project Evaluation and Review Technique) (Studi Kasus Proyek Perumahan Citra Turi). Jurnal Pelita Informatika, Volume 17, Nomor 1, Januari 2018.

Caesaron, D., \& Thio, A. (2015). Analisa Penjadwalan Waktu Dengan Metode Jalur Kritis dan PERT Pada Proyek Pembangunan Ruko (Jl. Pasar Lama No.20, Glodok). JIEMS
Journal of Industrial Engineering \& Management Systems Vol. 8, No 2, August 2015.

Iwawo, E. R. M., Tjakra, J., \& Pratasis, P. A. K. (2016). Penerapan Metode CPM Pada Proyek Konstruksi (Studi Kasus Pembangunan Gedung Baru Kompleks Eben Haezar Manado). Jurnal Sipil Statik Vol.4 No.9 September 2016 (551-558).

Nalhadi, A., \& Suntana, N. (2017). Analisa Infrastruktur Desa Sukaci-Baros Dengan Metode Critical Path Method (CPM). Jurnal Sistem dan Manajemen Industri Vol 1 No 1 Juli 2017, 35-42.

Polii, R. B., Walangitan, D. R. O., \& Tjakra, J. (2017). Sistem Pengendalian Waktu Dengan Critical Path Method (CPM) Pada Proyek Konstruksi (Studi Kasus : Menara Alfa Omega Tomohon). Jurnal Sipil Statik Vol.5 No.6 Agustus 2017 (363371).

Telaumbanua, T. A., Mangare, J. B., \& Sibi, M. (2017). Perencanaan Waktu Penyelesaian Proyek Toko Modisland Manado Dengan Metode CPM. Jurnal Sipil Statik Vol.5 No.8 Oktober 2017 (549-557). 